\title{
Mini Ovoid Brachytherapy
}

National Cancer Institute

\section{Source}

National Cancer Institute. Mini Ovoid Brachytherapy. NCI Thesaurus. Code C106077.

An internal radiation treatment technique in which a small diameter hollow metal sphere

filled with a radioactive source is placed inside the uterus for the treatment of

gynecological cancers. 